D0I: 10.12957/demetra.2017.25636

\title{
Atividade antitríptica em semente e produto alimentício de chia (Salvia hispanica L.)
}

\section{Anti-tryptic activity in seed and food product of chia (Salvia hispanica L.)}

Ana Paula Araúio de Souzal

Lorena Maria Araújo Marinheiro

Nascimentol

Vanessa Cristina Oliveira de Lima²

Fabiana Maria Coimbra de Carvalho²

Elizeu Antunes dos Santos ${ }^{2,3}$

Ana Heloneida de Araújo Morais ${ }^{4,5}$

1 Universidade Federal do Rio Grande do Norte, Curso de Nutrição, Centro de Ciências da Saúde. Natal-RN, Brasil.

${ }^{2}$ Universidade Federal do Rio Grande do Norte, Programa de Pós-graduação em Bioquímica, Centro de Biociências. Natal-RN, Brasil.

${ }^{3}$ Universidade Federal do Rio Grande do Norte, Departamento de Bioquímica, Centro de Biociências. Natal-RN, Brasil.

${ }^{4}$ Universidade Federal do Rio Grande do Norte, Programa de Pós-graduação em Nutrição, Centro de Biociências. Natal-RN, Brasil.

${ }^{5}$ Universidade Federal do Rio Grande do Norte, Departamento de Nutrição, Centro de Ciências da Saúde. Natal-RN, Brasil.

Agente financiador: Este trabalho recebeu 0 apoio financeiro do Programa Institucional de Bolsas de Iniciação Científica - REUNI/UFRN.

Correspondência / Correspondence

Ana Heloneida de Araújo Morais

E-mail: aharaujomorais@gmail.com

\section{Resumo}

Objetivo: Este estudo objetiva detectar a atividade antitríptica em semente e farinha comerciais de chia e isolar um inibidor de tripsina presente na semente. Metodologia: Foram realizados extração de proteínas, fracionamento com sulfato de amônio, cromatografia de afinidade, ensaio de inibição sobre tripsina, quantificação de proteínas e eletroforese em gel de poliacrilamida desnaturante. Resultados e discussão: A partir desses experimentos, detectou-se a atividade antitríptica no pico proteico retido na coluna de afinidade (RT), da farinha e semente, apresentando $51 \%$ e $64 \%$, respectivamente. Porém, não foram verificadas grandes quantidades de proteínas solúveis no RT, tanto da semente quanto da farinha, quando comparadas ao extrato bruto e frações proteicas. O inibidor de tripsina de semente foi isolado, indicando massa molecular estimada em, aproximadamente, 14,4 kDa. Conclusões: Diante dos resultados relativos à detecção da atividade antitrípica em semente e farinha comercial de chia, e isolamento do inibidor na semente, faz-se necessário o aprofundamento nas pesquisas acerca dessa molécula quanto as suas propriedades bioativas e segurança do consumo.

Palavras-chaves: Farinha. Sementes. Inibidores de Proteases. Tripsina.

\section{Abstract}

Objective: This study aimed to detect anti-tryptic activity in commercial chia seed and flour and to isolate a trypsin inhibitor present in the seed. Methodology: Protein extraction, ammonium 
sulfate fractionation, affinity chromatography, trypsin inhibition assay, protein quantification and sodium dodecyl sulfate polyacrylamide gel electrophoresis were performed. Results and discussion: From the retained protein peak in the affinity column, $51 \%$ and $64 \%$ of anti-tryptic activity for chia flour and seed were respectively found. Large amounts of soluble proteins were not observed in the retained protein peaks of both chia seed and flour, when compared to the crude extract and protein fractions. The trypsin inhibitor in the seed was isolated, with an estimated molecular mass of approximately $14.4 \mathrm{kDa}$. Conclusions: In view of the unprecedented results regarding the detection of anti-tryptic activity in commercial chia seed and flour, and isolation of the inhibitor in the seed, further research is needed on this new molecule, regarding its bioactive properties and safe consumption.

Key words: Flour. Protein. Enzyme Inhibitors. Trypsin.

\section{Introdução}

Na busca por alimentos funcionais que produzam benefícios para a saúde, vem se sobressaindo a utilização dos alimentos naturais reconhecidos como plantas medicinais para prevenção de doenças, e entre esses alimentos, sobressai a semente de Salvia hispanica L. ou, mais usualmente conhecida, a chia. ${ }^{1}$ A espécie Salvia hispanica L. pertence à família Lamiaceae, da subfamília Nepetoideae. ${ }^{2}$ Essa família contempla diversas plantas conhecidas como medicinais usadas na medicina popular como matéria-prima na manipulação de fármacos, fitoterápicos e produtos, entre formas sólidas, líquidas e semissólidas, como: pós, óleos essenciais e cremes, respectivamente. ${ }^{3}$

O cultivo da chia, portanto, vem sendo de grande interesse para o Brasil ${ }^{4}$ e está ganhando destaque pela população brasileira como alimento funcional, com vários atributos, como: os efeitos hipocolesterolêmico, sacietogênico e antioxidante, ${ }^{5-7}$ além da presença do ácido graxo ômega-3, de proteínas de alto valor biológico e de fibras dietéticas, principalmente as insolúveis. ${ }^{7,8}$ A chia ainda se destaca como fonte de importantes compostos fenólicos. ${ }^{9}$ Desse modo, a chia é bastante consumida pelos seus diversos benefícios para a saúde, como na prevenção e controle de problemas cardiovasculares, do diabetes e da obesidade..$^{10,11}$

A chia é tida como um alimento isento de regulação na maioria dos países devido à ausência de riscos à saúde e ao consumo histórico que possui, entretanto, no Brasil, de acordo com a Anvisa (Agência Nacional de Vigilância Alimentar), em virtude das alegações terapêuticas, a chia vem sendo considerada um alimento funcional básico, embora ainda não possua regulamentação. ${ }^{12}$ 
Atualmente, a indústria de fitoterápicos e de alimentos naturais saudáveis comercializa a chia como suplemento dietético, bem como a incorpora em diversas preparações de alimentos. ${ }^{1.13} \mathrm{~A}$ sua semente pode ser consumida na sua forma natural ou moída, como a farinha, além de outras aplicações, evidenciando, dessa maneira, a sua importância econômica e comercial.. ${ }^{14,15}$

Devido as suas propriedades nutricionais e alegações de saúde, essas sementes se destacam para a indústria alimentar, especialmente na formulação de alimentos saudáveis, sendo a farinha comercial de chia um dos produtos promissores na utilização em alimentos enriquecidos, de acordo com o estudo de Pizarro et al. ${ }^{16}$ Assim, pode-se melhorar a qualidade nutricional do alimento e garantir uma boa performance sensorial. ${ }^{17}$ Em virtude dos benefícios causados pela chia, o seu consumo vem aumentando vertiginosamente no mundo, tornando essa semente um produto em expansão.

Entretanto, entre os fatores que interferem numa dieta apropriada e que podem influenciar no estado nutricional de um indivíduo, estão os antinutricionais, presentes em alimentos naturais, principalmente nas sementes, que podem provocar efeitos fisiológicos adversos, como toxicidade e redução de crescimento em modelos experimentais, ou diminuir a biodisponibilidade de nutrientes, como os inibidores de proteases, as lectinas, os compostos fenólicos, entre outros. ${ }^{18}$ Porém, quanto aos inibidores enzimáticos, tem-se observado um potencial terapêutico em sua utilização heteróloga para o tratamento de alguns estados de doença. ${ }^{19-24}$

Embora os inibidores de tripsina estejam presentes naturalmente no reino vegetal, nas sementes de chia não existe relato na literatura sobre tal presença. Além disso, é importante investigar se esses inibidores comuns em sementes, também se apresentam e se mantêm nos seus produtos, como na farinha. Mesmo após os procedimentos industriais aos quais são submetidos alguns desses produtos, há evidências de que o processo pode não interferir na atividade dessas moléculas. Muitos inibidores possuem características termoestáveis comprovadas, como os inibidores de proteases. $^{19,25-28}$

Nesse sentido, verifica-se a importância de avaliar a presença da atividade antitríptica e isolar o inibidor de tripsina na semente e farinha comercial de chia, parâmetros ainda não estudados, levando em consideração a ação desses inibidores e a sua importância para a nutrição.

\section{Metodologia}

A semente e a farinha de chia (Salvia hispanica L.) utilizadas para o experimento, ambas produtos industrializados, foram adquiridas aleatoriamente no comércio local da cidade de Natal/RN. Os demais reagentes usados eram de grau analítico e obtidos da Sigma, St Louis, USA e VETEC Química Fina Ltda, Rio de Janeiro, Brasil. Os experimentos foram realizados no Laboratório de Química em Função de Proteínas Bioativas (LQFBP), no Departamento de Bioquímica da UFRN. 
A Extração proteica e o fracionamento com sulfato de amônio seguiram os protocolos já estabelecidos na rotina do laboratório. Inicialmente, as sementes foram trituradas em moedor refrigerado $\left(6^{\circ} \mathrm{C}\right)$. Para a extração proteica das sementes e da farinha comercial analisada, foi adicionado a cada amostra, separadamente, tampão Tris-HCl 0,05 mol. L ${ }^{-1}$, pH 7,5 na proporção de 1:10 (p/v). As amostras com tampão foram mantidas sob agitação constante à temperatura ambiente, por 3 horas, em seguida, centrifugadas a $10.000 \times \mathrm{g}, 4^{\circ} \mathrm{C}$, durante 30 minutos, e filtradas, para obtenção do extrato bruto (EB).

O fracionamento dos extratos brutos foi realizado com adição de sulfato de amônio utilizando três faixas de saturação, 0-30\%, 30-60\% e 60-90\%, sob agitação constante à temperatura ambiente. A cada etapa de adição de sal, as amostras eram deixadas overnight em câmara refrigerada a 4 ${ }^{\circ} \mathrm{C}$ e, em seguida, centrifugadas a $10.000 \times \mathrm{g}$ por 30 minutos, a $4 \stackrel{\circ}{\circ}$. Os precipitados coletados foram dialisados em membrana com poro $14 \mathrm{kDa}$, por $48 \mathrm{~h}$, a $4^{\circ} \mathrm{C}$ contra tampão Tris-HCl 0,05 mol. $\mathrm{L}^{-1}$, pH 7,5. Assim, foram obtidas, inicialmente, de cada produto alimentício, as frações 1 (F1) com saturação de $0-30 \%$ e realizados os mesmos procedimentos para obtenção das frações 2 (F2) e 3 (F3) com saturação de 30-60\% e 60-90\%, respectivamente; finalmente, as frações foram ressuspendidas em tampão Tris- $\mathrm{HCl} 0,05$ mol. $\mathrm{L}^{-1}$, pH 7,5.

No isolamento das proteínas das sementes e da farinha comerciais analisadas foi utilizada a coluna de afinidade com resina Sepharose CNBr 4B (Sigma, St Louis, Estados Unidos) derivatizada com tripsina, pré-equilibrada com tampão Tris-HCl 0,05 mol. L-1, pH 7,5, tendo sido aplicadas cerca de $10 \mathrm{mg}$ de proteínas da F2 das sementes e da farinha comercial analisadas. A coluna foi lavada com tampão Tris-HCl 0,05 mol. $\mathrm{L}^{-1}$, pH 7,5 para a remoção do material não retido. O material de interesse retido, na coluna, foi eluído com $\mathrm{HCl}$ 0,05 mol.L-1 e alíquotas de $5 \mathrm{~mL}$ foram coletadas

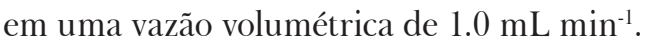

Todos os reagentes usados na técnica atenderam às especificidades exigidas pelo fabricante da resina. O perfil proteico foi determinado pelas leituras das absorbâncias em comprimento de onda a $280 \mathrm{~nm}$ medidas por espectrofotômetro (Amersham Biosciences - Ultrospec 2100 pro). Em seguida, as alíquotas que apresentaram maior conteúdo proteico foram reunidas e concentradas em um evaporador rotativo a vácuo, ressuspendidas em tampão Tris- $\mathrm{HCl}$ 0,05 mol. $\mathrm{L}^{-1} \mathrm{pH}$ 7,5 em volume mínimo suficiente para solubilizar as proteínas, denominadas isolado proteico retido em tripsina (RT).

As proteínas do EB, da F1, F2, F3 e do RT foram quantificadas pelo método de Bradford, ${ }^{29}$ utilizando albumina sérica bovina (BSA) como padrão, sendo as leituras das absorbâncias realizadas em comprimento de onda a $595 \mathrm{~nm}$ por espectrofotômetro (Amersham Biosciences - Ultrospec 2100 pro). Provas em branco foram realizadas e os ensaios foram feitos em triplicata. 
A atividade antitríptica foi determinada pela enzima tripsina a $0,3 \mathrm{mg} \cdot \mathrm{mL}^{-1}$, o BApNA (benzoilDL-arginina-p-nitroanilida) a 1,25 mmol. $\mathrm{L}^{-1}$ dissolvido em DMSO (1\%, v/v) como substrato ${ }^{30} \mathrm{e}$ $100 \mu \mathrm{L}$ dos EB, F1, F2, F3 e RT.

$\mathrm{O}$ resultado foi mensurado por meio da formação de $p$-nitroanilida monitorada pela leitura das absorbâncias em comprimento de onda de $410 \mathrm{~nm}$ medidas por espectrofotômetro (Amersham Biosciences - Ultrospec 2100 pro). Provas em branco foram realizadas e os ensaios foram feitos em triplicata. Seguindo os mesmos passos metodológicos, a atividade inibitória para tripsina foi repetida, submetendo-se previamente ao ensaio os RT de semente e farinha a condições desnaturantes $\left(100{ }^{\circ} \mathrm{C}\right.$ por 10 minutos).

Os resultados foram expressos em porcentual de inibição e em UI (unidade de inibição) $\mathrm{mg}^{-1}$ de proteína, sendo que $100 \%$ da atividade enzimática representam a ação da enzima tripsina sem a presença do inibidor, tendo, portanto, $0 \%$ de atividade antitríptica. A unidade de inibição representa a diferença entre a atividade enzimática da enzima e do material testado, sendo 1 UI igual a $0,01 \mathrm{~nm}$.

A avaliação do grau de pureza e determinação da massa molecular por eletroforese em Gel de Poliacrilamida Descontínuo e Desnaturante (SDS-PAGE) foi realizada de acordo com Laemmli, ${ }^{31}$ em gel de concentração a 4\% e gel de separação com concentração a 12\%. Foram aplicados, no gel de concentração, $15 \mu \mathrm{g}$ de proteínas do EB, F2 e RT. O gel foi corado de acordo com Weber \& Osborne, ${ }^{32} \mathrm{o}$ corante utilizado, nesse procedimento, foi preparado com Comassie Blue R-250 a $1 \%$, metanol 40\%, ácido acético $10 \%$ em água destilada.

Posteriormente, foi feita a revelação da eletroforese com nitrato de prata baseado no método descrito por Blum et al., ${ }^{33}$ utilizando-se de metanol 50\%, ácido acético $12 \%$ e formol $37 \%$ em água destilada para fixação, tiossulfato de sódio 0,01\%, etanol $30 \%$ e $50 \%$ em água destilada para lavagem e nitrato de prata $0,2 \%$ e formol $0,075 \%$ em água destilada para coloração. Por fim, foi realizada a revelação com carbonato de sódio 6\%, formol 0,05\% e tiossulfato de sódio 0,01\% em água destilada.

O marcador (Amersham Biosciences/GE Healthcare Life Sciences) usado possuía as seguintes massas moleculares conhecidas: 97,0 kDa de Fosforilase B; 66,0 kDa de Albumina (BSA); 45,0 kDa de Ovoalbumina; 30,0 kDa de Anidrase Carbônica; 20,1 kDa de Inibidor de Tripsina; e $14,4 \mathrm{kDa}$ de $\alpha$-lactoalbumina.

Os dados representam, pelo menos, três experimentos independentes e foram expressos com média e desvio-padrão, exceto quando indicado de outra maneira. Os dados estatísticos foram processados no software GraphPad prism 6.0. 


\section{Resultados e Discussão}

A chia é uma semente extremamente importante, já lhe tendo sido atribuída uma série de benefícios à saúde e também por ter apresentado, nesta pesquisa, em sua composição, os inibidores de tripsina. Neste estudo, o extrato bruto (EB) proteico obtido da semente e da farinha comerciais de chia apresentou 60\% (13 UIT/mg) e 82\% (93 UIT/mg) de atividade inibitória para tripsina, respectivamente.

As três frações F1, F2 e F3, obtidas nas faixas de concentração de sulfato de amônio (0\%-30\%, 30\%-60\% e 60\%-90\%), também foram avaliadas, apresentando 64\% (17 UIT/mg), 85\% (44 UIT/ $\mathrm{mg}$ ) e $92 \%$ (44 UIT/mg) de atividade inibitória para semente, respectivamente; e a farinha nas três frações F1, F2 e F3 mostrou 78\% (13 UIT/mg), 95\% (310 UIT/mg) e 51\% (100 UIT/mg) de atividade inibitória, respectivamente (Figura 1).

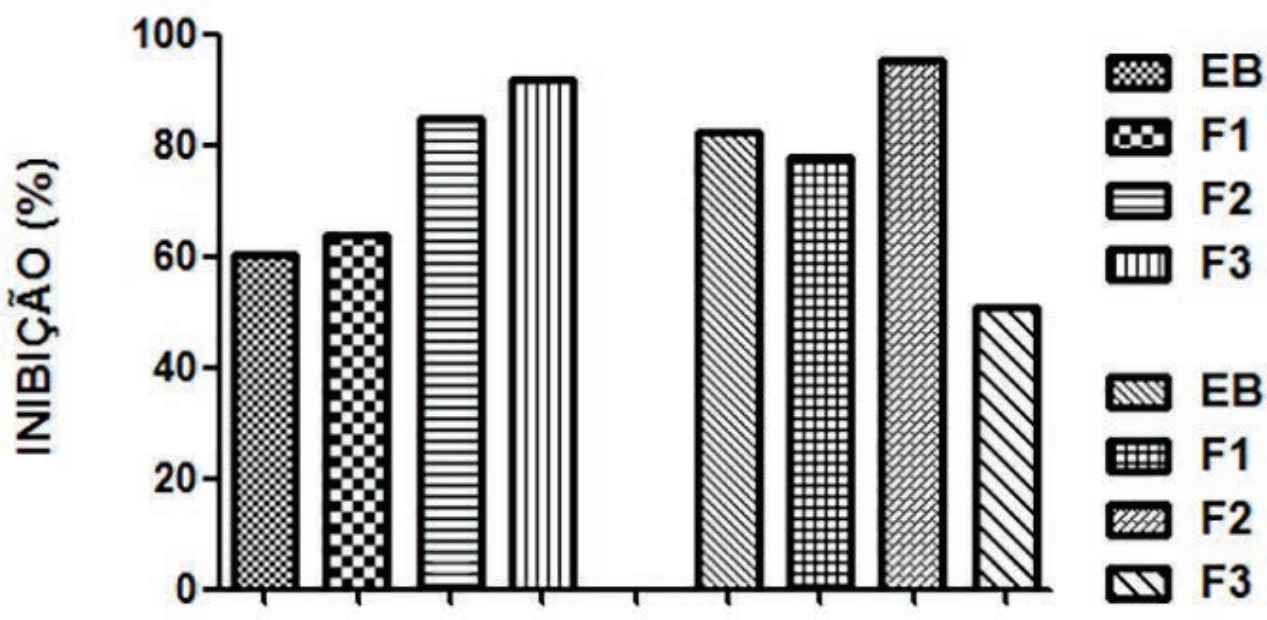

SEMENTE

FARINHA

Figura 1. Porcentual (\%) de Inibição da atividade da tripsina pelo extrato bruto e frações proteicas F1, F2 e F3 (saturação com sulfato de amônio em 0 - 30\%, 30 - 60\%, 60 - 90\%, respectivamente) de semente e farinha comerciais de chia (Salvia hispanica L.). Para o ensaio, utilizou-se $100 \mu \mathrm{l}$ do extrato bruto e das frações proteicas e BApNA 1,25 mmol. $\mathrm{L}^{-1}$ como substrato. 
Os resultados referentes à quantidade de proteínas solúveis para os passos de isolamento do inibidor em semente e farinha comerciais de chia revelaram na farinha que o EB $(0,320 \mathrm{mg} /$ $\mathrm{mL})$, a F1 $(2,215 \mathrm{mg} / \mathrm{mL})$ e F2 $(0,112 \mathrm{mg} / \mathrm{mL})$ indicaram quantidades expressivas de proteínas solúveis, no entanto, ao serem comparados com a F3 $(0,021 \mathrm{mg} / \mathrm{mL})$, percebe-se que, nessa fração, não foram detectadas grandes quantidades de proteínas, de acordo com o método utilizado. As sementes apresentaram uma quantidade de proteínas em EB $(1,662 \mathrm{mg} / \mathrm{mL}), \mathrm{F} 2(0,701 \mathrm{mg} / \mathrm{mL})$ e F3 $(0,755 \mathrm{mg} / \mathrm{mL})$ superior à farinha, e na F1 $(1,390 \mathrm{mg} / \mathrm{mL})$, inferior ao percebido na farinha.

Para isolamento do inibidor de tripsina de semente e farinha comerciais de chia, escolheuse a F2 (com 85\% e 95\% de inibição sobre tripsina, respectivamente) para aplicar na coluna de afinidade, pois, em vários estudos, como Bezerra et al. ${ }^{25}$ e Araújo et al.,${ }^{27}$ os inibidores de tripsina se concentraram em maior quantidade nessa fração. Ribeiro et al.; ${ }^{21}$ Serguiz et al..22 Lima et al.;23 Carvalho et al..$^{24}$ também isolaram inibidores de tripsina do partido da F2.

No isolamento desse inibidor de tripsina em semente e farinha comerciais de chia, o perfil proteico foi determinado a $280 \mathrm{~nm}$, e constatou-se que o pico proteico correspondente às proteínas retidas da F2 da semente na coluna de afinidade atingiu 64\% de inibição para atividade catalítica da enzima tripsina. Já o pico proteico retido da F2 da farinha apresentou atividade inibitória para tripsina de 51\%. Pode-se observar na Figura 2A e C que, na cromatografia de afinidade de tripsina, o RT apresentou um pequeno pico proteico, tanto em sementes como em farinha, indicando discreta quantidade de proteínas solúveis nesse passo do isolamento.

Esse dado foi confirmado pelo método de Bradford, ${ }^{29}$ em que o RT, tanto da semente quanto da farinha, não apresentou quantidade expressiva de proteínas $(0,001 \mathrm{mg} / \mathrm{mL})$ quando comparado com o EB e as outras frações proteicas. Portanto, não foi possível calcular a atividade antitríptica específica para o RT, já que a obtenção desse resultado depende da quantificação de proteínas.

Para estimar a massa molecular do inibidor de tripsina de semente e farinha de chia, realizouse a SDS-PAGE com o EB, a F1, F2, F3 e o RT. Comparando-se com as massas moleculares do marcador, é possível perceber, em sementes, que em, aproximadamente, 14,4kDa há uma predominância de proteínas da F2 retida em cromatografia de afinidade de tripsina.

Já para a farinha não foi possível visualizar proteínas no material retido à cromatografia de afinidade de tripsina como marcado na Figura 2B e D, aplicando o mesmo volume e quantidade nos dois géis, dos RT de semente e farinha, diferindo do observado no RT da semente de chia. No entanto, ainda assim, em farinha, o RT apresentou $51 \%$ de inibição para a atividade catalítica da tripsina. Essa mesma atividade antitríptica não foi mantida quando o RT de farinha de chia foi submetido a condições desnaturantes, demonstrando uma alta seletividade da cromatografia de afinidade de tripsina e, consequentemente, uma excelente especificidade das proteínas adsorvidas à coluna. 


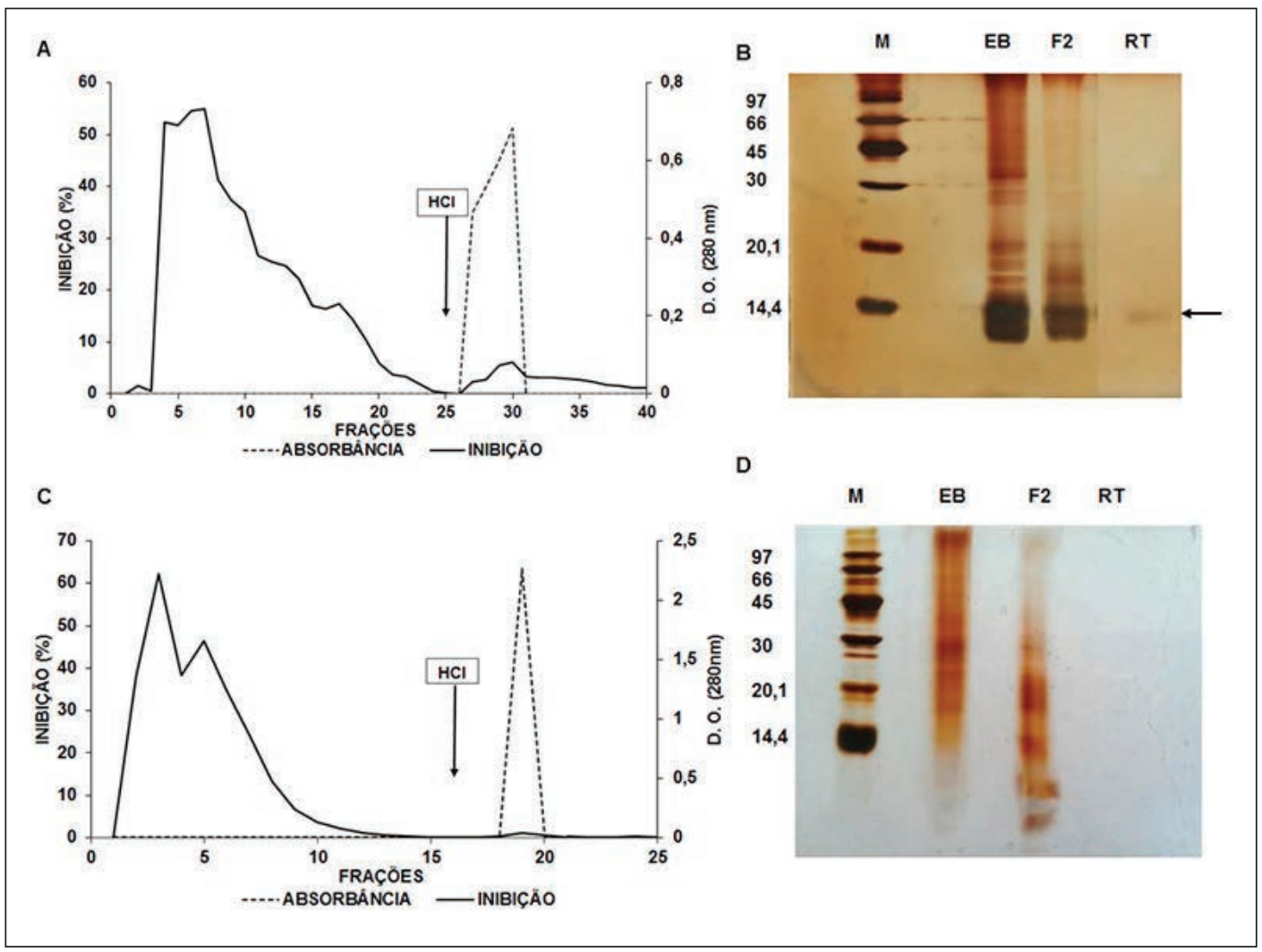

Figura 2. A e C) Perfil cromatográfico da F2 de semente e farinha comerciais de chia (Salvia hispanica L.), respectivamente, em cromatografia de afinidade Tripsina-Sepharose $\mathrm{CNBr} 4 \mathrm{~B}$. A atividade antitríptica foi verificada utilizando-se $100 \mu \mathrm{L}$ do RT. B e D) SDS-PAGE a 12\% corado com nitrato de prata, dos passos de isolamento do inibidor de tripsina de semente e farinha comerciais de chia (Salvia hispanica L.), respectivamente. M: Marcador; EB: Extrato Bruto - $15 \mu \mathrm{g}$; F2: Faixa de saturação com 30 - 60\% de sulfato de amônio - $15 \mu \mathrm{g}$; RT: Isolado Proteico com Atividade Antitríptica - $15 \mu \mathrm{g}$. A seta em "B” refere-se a 14,4 kDa.

Diante dos resultados, especulou-se que a quantificação proteica utilizando o reagente de Bradford composto por Comassie blue R 250 poderia não ter estimado adequadamente a quantidade de proteínas no processo de isolamento, já que existem substâncias que são interferentes nesse método. Entre essas substâncias, sabe-se que os polifenóis reagem com as proteínas, impedindo a formação de seu complexo com o corante. ${ }^{29,34}$ 
No entanto, o gel de SDS-PAGE mostra que essa interferência, especificamente, pode não ter ocorrido na obtenção do RT da farinha, já que a coloração do gel foi realizada com nitrato de prata e ele não revelou proteínas, porém, no extrato bruto e na F2, também aplicados no gel, observa-se a presença de bandas proteicas, demonstrando e confirmando, assim, que a quantidade dessas moléculas no material retido é ínfima. No RT das sementes, puderam ser visualizadas proteínas, bem como em todos os passos do seu isolamento.

Na semente de amaranto, outro pseudocereal, no estudo de Valdes-Rodriguez et al., ${ }^{35}$ o inibidor de tripsina foi purificado e apresentou, aproximadamente, $8 \mathrm{kDa}$. Entretanto, relacionado à atividade específica de inibidores de tripsina nessa mesma semente, em outro estudo foi detectada e variou de 938 a 5,454 UIT/g de proteína entre diferentes espécies de amaranto, tendo sido considerada baixa pelos autores. ${ }^{36}$

Essas diferenças, entre as mais diversas massas moleculares atribuídas aos inibidores de tripsina, atestam o que foi relatado por Santos et al., ${ }^{37}$ que os inibidores de protease variam muito em sua massa molecular e são classificados de acordo com a sua massa, havendo uma grande variação entre as famílias dos inibidores e as massas moleculares que eles apresentam. Sendo assim, são necessários outros estudos relacionados a sua purificação e caracterização para melhor classificá-lo entre as famílias de inibidores descritas na literatura.

Sabe-se que é generalizada a presença de inibidores enzimáticos em órgãos de reserva de plantas, como nas sementes, nas quais podem atuar como agentes regulatórios de proteases endógenas. ${ }^{37}$ Para a nutrição, diferente do estigma que os relacionam aos efeitos antinutricionais, esses inibidores possuem papel heterólogo e bioativo no processo de digestão de proteínas, apresentando efeito no controle da saciedade com consequente redução de peso em modelo experimental, tendo em vista que, a partir da diminuição da atividade de tripsina livre e consequente redução da quebra de proteínas e peptídeos, há elevação da concentração do hormônio sacietogênico CCK. 21,22,38-42

A detecção da atividade antitríptica e o isolamento de um inibidor de tripsina em sementes de chia são achados inéditos, uma vez que não foi encontrado, na busca da literatura científica realizada nas bases de dados, estudos anteriores que tenham analisado a presença desses inibidores. As proteínas da chia têm sido avaliadas quanto possíveis atividades biológicas, ${ }^{43,44}$ sendo relatada inclusive a presença de peptídeos com ação inibitória sobre a enzima conversora de angiotensina. ${ }^{45}$ No entanto, nada há sobre sua atividade antitríptica.

Devido à propriedade nutricional das sementes, a farinha comercial de chia tem sido considerada um dos produtos promissores na utilização em alimentos enriquecidos. ${ }^{16,17}$ É importante ressaltar que, com relação ao uso comercial e industrial da chia, a farinha torna-se um produto de fácil emprego, quando comparada à semente, principalmente pela possibilidade da sua inserção em preparações de produtos alimentares. 
Levando em conta que a chia é uma importante fonte de proteínas e que o extrato bruto e as frações proteicas apresentaram atividade inibitória para a tripsina, é válido ressaltar que o seu consumo pode trazer benefícios atribuídos a sua composição nutricional e aos compostos fenólicos. Vale acrescentar que existem, atualmente, muitos estudos sobre a ação de inibidores enzimáticos relacionados a efeitos benéficos à saúde, desde que se estabeleça a determinação de um consumo quantitativamente seguro e saudável.

\section{Conclusão}

Com base no presente estudo, verificou-se atividade antitríptica na semente e na farinha comerciais de chia e foi possível isolar um inibidor proteico de tripsina da semente de chia e estimar a sua massa molecular. Sabendo-se que a chia tem grande importância devido a sua composição nutricional e funcional, e diante das mais diversas atividades relatadas para os inibidores de tripsina, seriam necessárias mais pesquisas que venham testar as quantidades seguras para o consumo humano e a influência desses inibidores em alterações corporais.

\section{Colaboradores}

de Souza APA e Nascimento LMAM participaram da coleta, análise e interpretação dos dados e elaboração das figuras. de Lima VCO e de Carvalho FMC, da análise estatística e redação do manuscrito. dos Santos EA colaborou fornecendo o laboratório, recursos financeiros e revisão crítica do manuscrito. Morais AHA participou da concepção e desenho do estudo, obtenção de recursos financeiros, análise e interpretação de dados e redação do manuscrito.

Conflito de Interesses: Os autores declaram não haver conflito de interesses.

\section{Referências}

1. Muñoz LA, Cobos A, Diaz O, Aguilera JM. Chia Seed (Salvia hispanica): an ancient grain and a new functional food. Food Reviews International 2010; 29(4):394-408.

2. Cahill JP. Ethnobotany of chia, Salvia hispanica L. (Lamiaceae). Economic Botany 2003; 57(4):604-618.

3. Nascimento JE, Lacerda EU, Nascimento VT, Melo JG, Alves BS, Silva LGM, et al. Produtos à base de plantas medicinais comercializados em Pernambuco - Nordeste do Brasil. Acta Farm Bonaerense 2005; 24(1):113-22.

4. Migliavacca RA, Silva TRB, Vasconcelos ALS, Mourão Filho W, Baptistella JLC. O cultivo da chia no Brasil: futuro e perspectivas. Journal of Agronomic Sciences 2014; 3(no especial):161-179. 
5. Marineli RS, Moraes EA, Lenquiste SA, Godoy AT, Eberlin MN, Maróstica Jr MR. Chemical characterization and antioxidant potential of Chilean chia seeds and oil (Salvia hispanica L.). LWTFood Science and Technology 2014; 59(2):1304-1310.

6. Chicco AG, D’Alessandro ME, Hein GJ, Oliva ME, Lombardo YB. Dietary chia seed (Salvia hispanica L.) rich in alpha-linolenic acid improves adiposity and normalises hypertriacyl glycerolaemia and insulin resistance in dyslipaemic rats. Br J Nutr. 2009; 101(1):41-50.

7. Coates W. Chia: the complete guide to the ultimate superfood. New York: Sterling; 2012. 192 p.

8. Alonso-Calderòn A, Chávez-Bravo E, Rivera A, Montalvo-Paquini C, Arroyo-Tapia R, MonterrosasSantamaria M, et al. Characterization of black chia seed (salvia hispanical.) and oil and quantification of $\beta$-sitosterol. Int Res J Biological Sci. 2013; 2(1):70-72.

9. Reyes-Caudillo E, Tecante A, Valdivia-López MA. Dietary fibre content and antioxidant activity of phenolic compounds present in Mexican chia (Salvia hispanica L.) seeds. Food Chemistry 2008; 107(2):656-663.

10. Jenkins AL, Brissette C, Jovanovski E, Au-Yeung F, Ho HVT, Zurbau A, et al. Effect of SalbaChia (Salvia Hispanica L.), an ancient seed, in the treatment of overweight and obese patients with type 2 Diabetes: a double-blind, parallel, randomized controlled trial. The FASEB Journal 2016; 30(1):126.2-126.

11. Valdivia-López MA, Tecante A. Chapter two-Chia (Salvia hispanica): a review of native mexican seed and its nutritional and functional properties. Adv Food Nutr Res. 2015; 75:53-75.

12. Brasil. Agência Nacional de Vigilância Sanitária. Guia para comprovação da segurança de alimentos e ingredientes. Brasília: ANVISA; 2013. 41 p

13. Martínez-Cruz O, Paredes-López O. Phytochemical profile and nutraceutical potential of chia seeds (Salvia hispanica L.) by ultra high performance liquid chromatography. J Chromatogr. 2014; 1346:43-48.

14. Coelho MS, Salas-Mellado MM. Review: Chemical composition, functional properties and technological applications of chia (Salvia hispanica L) seeds in foods. Braz J Food Technol. 2014; 17(4):259-268.

15. Moreira R, Chenlo F, Torres MD. Effect of chia (Sativa hispanica L.) and hydrocolloids on the rheology of gluten-freedoughs based on chestnut flour. LWT - Food Science and Technology 2013; 50(1):160-166.

16. Pizarro PL, Almeida EL, Sammán NC, Chang YK. Evaluation of whole chia (Salvia hispanica L.) flour and hydrogenated vegetable fat in pound cake. Food Science and Technology 2013; 54(1):73-79.

17. Vázquez-Ovando A, Rosado-Rubio JG, Chel-Guerrero L, Betancur D. Physicochemical properties of a fibrous fraction from chia (Salvia hispanica L.). LWT-Food Science and Technology 2009; 42(1):168-173.

18. Gilani GS, Xiao CW, Cockell KA. Impact of anti-nutritional factors in food proteins on the digestibility of protein and the bioavailability of amino acids and on protein quality. British Journal of Nutrition 2012; 108(S2):S315-S332. 
19. Gonçalves R, Mateus N, Freitas V. Biological relevance of the interaction between procyanidins and trypsin: a multitechnique approach. J Agric Food Chem 2010; 58(22):11924-11931.

20. Machado RJA, Monteiro NKV, Migliolo L, Silva ON, Pinto MFS, Oliveira AS, et al. Characterization and pharmacological properties of a novel multifunctional kunitz inhibitor from Erythrina velutina seeds. PloS One 2013; 8(5):1-14.

21. Ribeiro JA, Serquiz AC, Silva PF, Barbosa PB, Sampaio TB, Araújo Junior RF, et al. Trypsin inhibitor from Tamarindus indica L. seeds reduces weight gain and food consumption and increases plasmatic cholecystokinin levels. Clinics 2015; 70:136-143.

22. Serquiz AC, Sátiro DSP, Lima VCO, Rocha LRM, Oliveira CN, Sampaio TBM, et al. The effect of a high calorie diet containing a peanut candy on weight loss. Internacional Food Research Journal 2016; 23(1):248-256.

23. Lima VCO, Machado RJA, Monteiro NKV, Lyra IL, Camilo CS, Serquiz AC, et al. Gastroprotective and anti-elastase effect of protein inhibitors from Erythrina velutina seeds in an experimental ulcer model. Biochem Cell Biol. 2016. Disponível em: http://www.nrcresearchpress.com/doi/ pdfplus/10.1139/bcb-2016-0034

24. Carvalho FMC, Lima VCO, Costa IS, Medeiros AF, Serquiz AC, Lima MCJS, et al. A Trypsin Inhibitor from Tamarind Reduces Food Intake and Improves Inflammatory Status in Rats with Metabolic Syndrome regardless of weight loss. Nutrients 2016; 8(10):544.

25. Bezerra ADL, Barbosa CRM, Carvalho FMC, Serquiz AC, Morais AHA. Atividade antitríptica de proteínas em polpas e sementes de frutas tropicais. Rev Bras Frutic. 2014; 36(2):408-416.

26. Carvalho FMC, Dantas MBVC, Bezerra ADL, Machado RJA, Santos EA, Morais, AHA. Compostos fenólicos e atividade anti-trípica em três variedade de uvas [Internet]. Revista Brasileira de Inovação Tecnológica em Saúde 2014; 4(1):39-50.

27. Araújo JM, Alves JC, Peixoto TKON, Medeiros AF, Machado RJA, Serquiz AC, et al. Determinação da atividade anti-tríptica em proteínas de produtos do amendoim isoladas por cromatografia de afinidade. Quím Nova 2014; 37(10):1618-1623.

28. Serquiz AC, Machado RJA, Serquiz RP, Lima VCO, Carneiro MAA, Maciel BLL, et al. Supplementation with a new trypsin inhibitor from peanut is associated with reduced fasting glucose, weight control, and increased plasma CCK secretion in an animal model. J Enzyme Inhib Med Chem. 2016; 31(6):1261-1269.

29. Bradford MM. A rapid and sensitive method for the quantitation of microgram quantities of protein utilizing the principle of protein-dye binding. Anal Biochem. 1976; 72(1):248-254.

30. Kakade ML, Simons N, Liener IE. An evaluation of natural vs synthetic substrates for measuring the antitryptic activity of soybean samples. Cereal Chem. 1969; 46:518-526.

31. Laemmli UK. Cleavage of structural proteins during the assembly of the head of bacteriophage T4. Nature 1970; 227(5259):680-685.

32. Weber K, Osborn M. The reliability of molecular weight determinations by dodecyl sulfatepolyacrylamide gel electrophoresis. J Biol Chem. 1969; 244(16):4406-4412. 
33. Blum H, Beier H, Gross HJ. Improved silver staining of plant proteins, RNA and DNA in polyacrylamide gels. Electrophoresis 1987; 8(2):93-99.

34. Mattoo RL, Ishaq M, Saleemuddin M. Protein assay by coomassie brilliant blue G-250-binding method is unsuitable for plant tissues rich in phenols and phenolases. Analytical Biochemistry 1987; 163(2):376-384.

35. Valdes-Rodriguez S, Segura-Nieto M, Chagolla-Lopez A, Vargas-Cortina AV, Martinez-Gallardo N, Blanco-Labra A. Purification, characterization, and complete amino acid sequence of a trypsin inhibitor from amaranth (Amaranthus hypochondriacus) seeds. Plant Physiology 1993; 103(4):1407-1412.

36. Correa AD, Jokl L, Carlsson R. Chemical constituents, in vitro protein digestibility and presence of anti-nutritional substances in amaranth grains. Arch Latinoam Nutr. 1986; 36(2):319-325.

37. Santos EA, Oliveira AS, Rabêlo LMA, Uchôa AF, Morais AHA. Affinity chromatography as a key tool to purify protein protease inhibitors from plants. In: Magdeldin S, editor. Affinity chromatography. Rijeka, Croatia: In Tech; 2012. p. 211-244.

38. Kissileff HR, Pi-Sunyer FX, Thornton J, Smith GP. C-terminal octapeptide of cholecystokinin decreases food intake in man. Am J Clin Nutr. 1981; 34(2):154-160.

39. Visvanathan R, Jayathilake C, Chaminda JB, Liyanage R. Health $\square$ beneficial properties of potato and compounds of interest. J Sci Food Agric. 2016; 96(15):4850-4860.

40. Nakajima S, Hira T, Tsubata M, Takagaki K, Hara H. Potato extract (Potein) suppresses food intake in rats through inhibition of luminal trypsin activity and direct stimulation of cholecystokinin secretion from enteroendocrine cells. J Agric Food Chem. 2011; 59(17):9491-9496.

41. Komarnytsky S, Cook A, Raskin I. Potato protease inhibitors inhibit food intake and increase circulating cholecystokinin levels by a trypsin-dependent mechanism. Int J Obes. 2011; 35(2):236-243.

42. Chen W, Hira T, Nakajima S, Tomozawa H, Tsubata M, Yamaguchi K, et al. Suppressive effect on food intake of a potato extract (Potein $\left.{ }^{\circledR}\right)$ involving cholecystokinin release in rats. Biosci Biotechnol Biochem. 2012; 76(6):1104-1109.

43. Olivos-Lugo BL, Valdivia-López MA, Tecante A. Thermal and physicochemical properties and nutritional value of the protein fraction of Mexican chia seed (Salvia hispanica L.). Food Sci Technol Int. 2010; 16(1):89-96.

44. Segura-Campos MR, Salazar-Vega IM, Chel-Guerrero LA, Betancur-Ancona DA. Biological potential of chia (Salvia hispanica L.) protein hydrolysates and their incorporation into functional foods. LWT - Food Science and Technology 2013; 50(2):723-731.

45. Segura-Campos MR, González FP, Guerrero LC, Ancona DB. Angiotensin I-converting enzyme inhibitory peptides of chia (Salvia hispanica L.) produced by enzymatic hydrolysis. Int J Food Sci. 2013; 2013:1-8. 
